\title{
Hericium: A review of the cultivation, health-enhancing applications, economic importance, industrial, and pharmaceutical applications
}

\author{
Gonkhom $D^{1,2}$, Luangharn $T^{2}$, Raghoonundon $\mathrm{B}^{1,2}$, Hyde $\mathrm{KD}^{1,2}$, Stadler $\mathrm{M}^{3}$ and \\ Thongklang $\mathbf{N}^{1,2^{*}}$
}

\author{
${ }^{1}$ School of Science, Mae Fah Luang University, Chiang Rai 57100, Thailand \\ ${ }^{2}$ Center of Excellence in Fungal Research, Mae Fah Luang University, Chiang Rai 57100, Thailand \\ ${ }^{3}$ Department of Microbial Drugs, Helmholtz Centre for Infection Research (HZI), and German Centre for Infection \\ Research (DZIF), partner site Hannover/Braunschweig, Inhoffenstrasse 7, 38124 Braunschweig, Germany
}

Gonkhom D, Luangharn T, Raghoonundon B, Hyde KD and Thongklang N (2021) - Hericium: A review of the cultivation, health-enhancing applications, economic importance, industrial, and pharmaceutical applications. Fungal Biotec 1(2), 118-130, Doi 10.5943/FunBiotec/1/2/8

\begin{abstract}
Hericium is a genus of edible mushroom with proven medicinal efficacy. The mycelium and basidiomata contain many nutrients and bioactive compounds with therapeutic uses. Recent and emerging evidence has shown that Hericium is helpful to various diseases with medicinal properties, such as anti-oxidant, anti-cancer, anti-diabetic, anti-hyperglycemic, hypolipidemic properties, anti-inflammatory, anti-microbial, anti-viral, and hepatoprotective. Over the past decade, many studies have been done on Hericium cultivation to produce enough basidiomata for culinary and medical purposes, due to its rarity in natural habitat. The purpose of this review is to provide the cultivation methods including indoor-outdoor cultivations and submerged culture methods, health-enhancing applications, economic importance, and industrial applications of Hericium mushroom.
\end{abstract}

Keywords - cultivation - economical - industrial applications - medicinal mushroom

\section{Introduction}

Species of Hericium Pers. (1794), are commonly considered as traditional food and traditional folk medicines in China (Shao et al. 2019). They are native to North America and found in the wild in East Asia countries and India (Das et al. 2011). They are rarely found in European countries but are common in Japan and North America. Hericium species have a variety of common names for e.g., lion's mane mushroom, hóutóugū, yamabushitake, monkey's head, Pom Pom, Bear's head, Hog's head fungus, Whitebeard, Old-man's beard, and Bearded tooth (Thongbai et al. 2015, Sangtitanu et al. 2020).

Hericium is a genus of edible and medicinal mushrooms that belongs to the family Hericiaceae, order Russulales, and class Agaricomycetes (Kirk et al. 2008, He et al. 2019). Hericium comprises 34 species with 66 taxon names listed in Index Fungorum (Index Fungorum 2021) and 23 species records in Notes of Genera in Basidiomycota (He et al. 2019). The basidiomata in this genus are white and fleshy, growing on dead trees or dried woods, the basidiomata are similar to fragile iced thorns which either hang from a branch, supporting the framework or as a tough unbranched cushion of tissue (Volk \& Westmoreland 2009, Hallenberg et al. 2012, Kuo 2014). The dangling spines easily identify a mature specimen (Ouali et al. 2020). The 
spines are arranged by clusters or often in rows (Park et al. 2004). Identifying immature specimens can be more difficult since they tend to start as a single clump and develop their branches as they age (Mykoweb 2015). They have no caps and consist of spiny spherical to ellipsoid amyloid spores that are either smooth or covered with very fine warts (Kuo 2014). Their hyphae are gloeopleurous and filled with oil drops (Kuo 2014).

Hericium has extensively been studied for cultivation and medical purposes. Historically, the first strains of Hericium were cultivated in China and belonged to the species H. erinaceus (Suzuki \& Mizuno 1997), which later became the commercial Hericium strain for cultivation (Sawant 2021). Hericium species grow slowly and inhabit the top of beech or oak trunks in pairs, in wild forests (Jiang et al. 2014). The hardwood sawdust is the most suitable substrate for H. erinaceus in order to attain a high yield in mushroom cultivation (Hu et al. 2008). Atila (2019) reported that a reduction in the concentrations of lignin content with low cellulose of various sawdust had a positive effect on the productivity of Hericium.

Most Hericium species have long been examined for medicinal compounds. Several bioactive compounds from Hericium were found to have a therapeutic potential to immune-stimulating effects (Chen et al. 2017, Sheng et al. 2017). Hericium is a great source for novel therapeutic compounds, and it has been found to have effects on nerves and the brain (Chong et al. 2020). Most of the neurotrophic compounds have effects on the human nerve cell, and neurogenerative diseases such as Alzheimer's disease (AD) and Parkinson's disease (PD) (Zhang et al. 2016, Ratto et al. 2019, Chong et al. 2020, Ryu et al. 2021). There have been many reports about the bioactive secondary metabolites, such as phenols, polyketides, terpenes (De Silva et al. 2013), polysaccharides, lipopolysaccharides, glycoproteins, pyrone, alkaloids, terpenoids, steroids, and non-ribosomal peptides (Keong et al. 2007, Chen et al. 2017).

In this review, we provide the indoor-outdoor cultivation methods, health benefits, economic significance and industrial applications of Hericium.

\section{Cultivation of Hericium}

The cultivation methods for Hericium differ depending on the use propose of the mushroom for e.g., for basidiomata production or for chemical investigations.

\section{Cultivation methods for mushroom production and biomass}

The adaptability of wild Hericium growth is not entirely clear, but it depends on the microbiological condition of the substrate surface, basic nutrition, and environmental restrictions (Bruhn et al. 2000). However, there are two methods to grow Hericium species including outdoor and indoor cultivation. Some Hericium species have been cultivated as a commercially including $H$. erinaceus, H. abietis, and H. americanum (Xiao \& Chapman 1997, Hassan 2007, Sokół et al. 2015, Atila et al. 2017, Bunroj et al. 2017). Ko et al. (2005) reported that $H$. americanum, H. coralloides, and $H$. erinaceus fruiting bodies are usually produced on oak sawdust substrate. Additionally, sawdust substrates from various deciduous trees are also considered as the main substrate for commercial cultivation (Oei 2016).

\section{Outdoor cultivation}

The first wide scale cultivation of Hericium originated in China (Sokół et al. 2015). Traditional outdoor cultivation is seasonally done in the shade of a tree by making mushroom beds on unprocessed logs. The wood chips overgrown with the mycelium of Hericium mushroom were inoculated into dry logs or fresh tree stumps and incubated with high humidity, after which the mycelium will grow on the substrate (Ahmadi \& Farsi 2017). The Hericium mycelia can grow on sawdust of Acer species (maple), Mangifera indica (mango), Populus sp. (populus), Psidium guajava (common guava) and Quercus sp. (oak) (Pathmashini et al. 2008, Stamets 2011). Several studies have recommended wood from coniferous tree species including Pinus taeda and P. ponderosa as the substrate composition for Hericium cultivation (Croan 2004). Outdoor production of Hericium produces good yield on logs of Acer sp. (maple), Fagus sp. (beech), Quercus sp. (oak), 
Ulmus sp. (elm), and other hardwoods (Stamets 2011, Grace \& Mudge 2015). Mushroom totem inoculation method can also be used for logs or stumps outdoor cultivation using sawdust and spawn (Grace \& Mudge 2015, Soderberg 2019).

\section{Indoor cultivation}

Most of the demands for Hericium from the commercial market are fulfilled through indoor cultivation in sawdust and wood bags (Grace \& Mudge 2015). Current research is dedicated to indoor cultivation systems, largely because indoor systems are more lucrative and can be studied more efficiently (Bruhn et al. 2000).

An intensive cultivation method needs to be used in order to obtain high yields of good quality (Dai \& Dong 2014). Most of the intensive cultivation for this mushroom is typically done in bottles or bags (Imtiaj \& Rahman 2008). The culture substrate needs to be sterilized and it must be made from a heat-resistant material such as polypropylene (Ko et al. 2005, Sokół et al. 2015). Several reports have proved that the use of agricultural by-products as supplements increases the mycelial growth of Hericium (Suwanno et al. 2019 Xiao \& Chapman (1997) reported conifer sawdust supplemented with wheat bran, calcium sulfate and sugar as the main substrate for the growth of H. abietis. Zhang (2000) found that the favored substrate for H. erinaceus mycelium growth contains mainly corncobs and cotton chaffs supplemented with wheat bran, corn meal, gypsum and sugar. Furthermore, Bunroj et al. (2017) reported para rubber sawdust supplemented with rice bran, gypsum, dolomite, yeast, leucaena leaf meal, magnesium sulphate and EM solutions (Effective Microorganism), as effective for production of Hericium basidiomata. Moreover, other substrates reported as beneficial for $H$. americanum mycelial growth include oak sawdust, olive press cake, and cottonseed hulls (Atila et al. 2017).

\section{Mushroom harvesting and production}

Mushroom cultivation mostly uses plastic bags with small holes so as the basidiomata are able to easily come off, thus reducing the loss of production during harvesting operations (Stamets 2011). It usually takes 33-40 days for the primordia to appear and 10 days after primordia appearance, the first flush of Hericium fruiting bodies can be harvested (Ko et al. 2005). Several Hericium cultivation experiments, the cultivation bags are capable of producing fruiting bodies for around 3-4 flush per bag (Bunroj et al. 2017). Moreover, mushroom production depends on the environmental factors including climate factors, especially temperature inducer the effect of the mushroom product (Andrew et al. 2018). Hericium mushrooms should be harvested when the thorns are very long, but before the tops of the fruit mass weaken and become noticeably yellow or pink (Adamant 2019). Picking mushrooms in this fashion makes the harvesting process faster. Relative humidity in the growing room should be reduced to $80 \%$ for $4-8$ hours before harvesting in order to reduce surface moisture and extend shelf life (Stamets 2011).

\section{Submerged culture: cultivation methods for the production of bioactive compounds}

Submerged culturing of Hericium can produce bioactive secondary metabolites that might not be found in their basidiomata (Elisashvili 2012). Critical conditions for the optimization of bioactive compounds include the monitoring of nutrient consumption and respiration (Thongbai et al. 2015). Several studies have tried to ascertain the best conditions for growing and producing mushrooms so that the fungi produce higher biomass, thus increasing the availability of more essential bioactive metabolites (Lee et al. 2004). Wolters et al. (2015) reported that submerged cultivation of $H$. erinaceus is the best method to produce erinacine $\mathrm{C}$. The final inoculation ratio 5:10 (v/v) at $\mathrm{pH} 7.5$ of $100 \mathrm{mM}$ hydroxyethyl piperazineethanesulfonic acid (HEPES), produces high biomass of erinacine $\mathrm{C}$ at 2.73 gram/liter.

Nevertheless, there have also been many studies showings that some important secondary metabolites are also present on basidiomata of $H$. erinaceus growing on different substrates, such as artificial media and cheap agricultural substrates (Kulisic et al. 2004, Hu et al. 2008, Malinowska et al. 2009, Cui et al. 2010, Lee et al. 2010, Zhang et al. 2012). Wittstein et al. (2016) reported the production of a bioactive compound of $H$. coralloides could be used basidiomata by homogenized 
mechanically and stirred with acetone then separation of biomass by filtration. With the increasing demand for bioactive compounds from this mushroom, its cultivation for fruiting bodies is much needed. At present, there are still studies being done on mycelial cultivation so as more extracts are needed to meet the needs of consumers.

\section{Health-enhancing applications of mushrooms}

\section{Mushroom nutrient}

Hericium is a good source of dietary supplements in nutritional and medical food (Fernandes et al. 2021). In general, mushrooms contain $90 \%$ of water and $10 \%$ of dry matter (Ho et al. 2020). The composition of mushrooms depends on the growing medium and cultivation conditions (Badalyan 2003). Hericium is a relatively good source of several nutrients including free amino acids, especially glutamic acid, and numerous volatile compounds (Friedman, 2015). In addition, Hericium contains sugar, fat content, and protein content in fruiting bodies (Ulziijargal \& Mau 2011). The basidiomata contains various amounts of nutritional macro-micro elements as well as low amounts of potentially toxic elements (Friedman 2015, Atila 2019). The nutritional content depends not only on environment and maturation stage but also on the species (Table 1).

Table 1 Nutrient contents of basidiomata of Hericium.

\begin{tabular}{|c|c|c|c|}
\hline \multirow[t]{2}{*}{ Properties } & \multicolumn{3}{|l|}{ Hericium species } \\
\hline & $\begin{array}{l}\text { H. americanum } \\
\text { (Atila et al. 2017) }\end{array}$ & $\begin{array}{l}\text { H. coralloides } \\
\text { (Heleno et al. 2015) }\end{array}$ & $\begin{array}{l}\text { H. erinaceus } \\
\text { (Stamets 2011, Heleno et } \\
\text { al. 2015) }\end{array}$ \\
\hline $\operatorname{Ash}(g / 100 g)$ & 6.4 & 9.31 & 3.49 \\
\hline $\begin{array}{l}\text { Carbohydrate } \quad(\mathrm{g} / \\
100 \mathrm{~g})\end{array}$ & - & 81.06 & 79.36 \\
\hline Calcium (g/ 100g) & 0.026 & 0.0044 & 0.0013 \\
\hline Dietary fiber (\%) & - & 44.28 & 41.32 \\
\hline Energy (kcal/ 100 g) & - & 394.67 & 374.79 \\
\hline Fat $(g / 100 g)$ & - & 2.38 & 1.75 \\
\hline Iron $(\mathrm{g} / 100 \mathrm{~g})$ & $4.95-7.22$ & 0.00677 & 0.0203 \\
\hline Mannitol & - & 3.86 & 5.63 \\
\hline Magnesium (g/ 100g) & $0.063-0.133$ & 0.0085 & 0.1230 \\
\hline Phosphorus (g/ 100g) & $0.99-2.12$ & - & 0.0012 \\
\hline Potassium (g/ 100g) & $2.66-3.58$ & 1.188 & 0.0044 \\
\hline Protein (g/ 100g) & $8.5-23.7$ & 15.4 & 36.4 \\
\hline Sodium (g/ 100g) & $0.134-0.178$ & 0.586 & 0.0012 \\
\hline Total sugar & - & 10.79 & 23.63 \\
\hline Trehalose & - & 0.68 & 0.54 \\
\hline
\end{tabular}

In addition, Hericium has a high average nutritional profile (Atila et al. 2021). The healthpromoting properties responsible for the mushroom's nutritional value include amino acids, proteins, carbohydrates, fatty acids, vitamins, and minerals (Friedman 2015).

\section{Medicinal property}

Hericium mushrooms have long been considered to have medicinal value. However, these mushrooms have vast prospects as a source of medicinal compounds (Elkhateeb et al. 2019). These have been investigated in vivo and in vitro model systems (Chen et al. 2019). Many bioactive substances with immunomodulatory effects have been isolated from this mushroom (Sheng et al. 2017). These include high-molecular weight compounds such as polysaccharides and lowmolecular weight compounds such as polyketides (Thongbai et al. 2015). The typical bioactive 
compounds isolated from Hericium include pyrone and alkaloids, terpenoids, sterols, and nonribosomal peptides (Table 2).

Hericium is a great source of novel therapeutic compounds (Chong et al. 2020). Most of the neurotrophic compounds have positive effects on the human nerve cell and neurogenerative diseases such as Alzheimer's disease, Parkinson's disease, Prion disease, Motor neurone disease, Huntington's disease, Spinocerbellar ataxia, and Spinal muscular atrophy (Zhang et al. 2016, Ratto et al. 2019, Chong et al. 2020). Ryu et al. (2021) reported that hericerin and isohericerinol A increase and regulate the number of neurons by nerve growth factor synthesis and brain-derived neurotrophic factors, in combination with synaptophysin. hericerin and isohericerinol A can promote neuron differentiation and neuron growth, which may be useful for both preventive and therapeutic use in neurodegenerative diseases (Li et al. 2018).

Table 2 The typical bioactive compounds isolated from Hericium.

\begin{tabular}{|c|c|c|}
\hline $\begin{array}{l}\text { Hericium } \\
\text { species }\end{array}$ & Compounds & References \\
\hline $\begin{array}{l}\text { Hericium. } \\
\text { coralloides }\end{array}$ & $\begin{array}{l}\text { corallocins A-C; hericerin; [5-(2E)-3',7'-dimethyl-2',6'- } \\
\text { octadienyl]-4-hydroxy-6-methoxy-1-isoindoline }\end{array}$ & Wittstein et al. (2016) \\
\hline H. erinaceus & $\begin{array}{l}\text { cyatha-3,12-diene; D-Arabinitol; erinapyrones A, B, C; } \\
\text { erinaceolactone A, C; erinacines A, B, C, E, F, G, H, I, S, } \\
\text { Z1; erinacerin M; erinacol; hericerin; herierin III; hericanal } \\
\text { A; hericene A; hericenones A, B, C, D, E, F, G, H; } \\
\text { isohericerin; isohericerinol A; methyl linoleate; } \\
\text { orsellinaldehye; polyphenols; polysaccharides; N-De } \\
\text { phenylethyl isohericerin; 11-O-acetylcyathin A3; 1-D- } \\
\text { arabinitol-monolinoleate; } \\
\text { methylbenzene; 4-chloro-3,5-dihydroxy-1,3-dimethoxy-5- } \\
\text { [30,70-Dimethyl-20,60-octadienyl]-2-formyl-3-hydroxy-5- } \\
\text { methyoxybenzylalcohol } \\
\text { erinacine Z2; erinacines A, B, C, E, F; CJ14.258 }\end{array}$ & $\begin{array}{l}\text { Miyazawa et al. (2012) } \\
\text { Wolters et al. (2015) } \\
\text { Sokół et al. (2015) } \\
\text { Chen et al. (2017) } \\
\text { Rupcic et al. (2018) } \\
\text { Ryu et al. (2021) }\end{array}$ \\
\hline
\end{tabular}

Furthermore, the compounds have been traditionally used in China for the prevention and treatment of human diseases. The important assignment is to describe the bioactive compounds of Hericium and their medicinal properties. It has been demonstrated that this mushroom possesses anti-oxidant (Jiang et al. 2019), anti-cancer (Younis 2017), anti-diabetic (Wu \& Xu 2015), antihyperglycemic (Yao et al. 2021), hypolipidemic (Liang et al. 2013), anti-inflammatory (Hetland et al. 2020), anti-microbial (Vamanu \& Voica 2017), anti-viral (Liu 2019), anti-fungal (Song et al. 2020), and hepatoprotective properties (Wang et al. 2019).

\section{Hericium as antioxidant}

Miles \& Chang (2004) reported that Hericium prevents oxidation damage to cell DNA. According to Jiang et al. (2019), the effects of anti-oxidants are diverse, which may be due to external factors such as different components by the different extraction conditions having different anti-oxidant mechanisms. Atila et al. (2018) reported that the addition of olive cakes to the sawdust substrates for Hericium cultivation resulted in noticeable effects of its anti-oxidant activity. Moreover, Atila et al. (2018) recommended the cottonseed husks and olive cakes with wheat bran to increase the yield of Hericium.

\section{Hericium as anti-cancer}

Cancer is the world's leading cause of death (Younis 2017). Hericium has many medicinal properties such as anti-cancer activity (Blagodatski et al. 2018). Younis (2017) reported that polar extracts from $H$. erinaceus could be a good natural anti-cancer compound source. Moreover, 
Hericium extracts (HTJ5 and HTJ5A) have anti-hepatic and are effective against liver cancer, colon cancer, and gastric cancer in vitro and tumor xenografts bearing in mice in vivo (Blagodatski et al. 2018). This compound has potential as an anti-cancer agent for the treatment of gastrointestinal cancer used alone and/or in combination with clinical chemotherapy (Li et al. 2014).

\section{Anti-diabetic, anti-hyperglycemic and hypolipidemic properties of Hericium}

Liang et al. (2013) reported that the administration of the aqueous extract of $H$. erinaceus (AEHE) in streptozotocin (STZ) induced diabetic rats, resulting in lower blood glucose levels and higher insulin levels in the blood. The AEHE treatment also reduces fat disorders (Liang et al. 2013). The AEHE of $H$. erinaceus management increased the activities of catalase, superoxide dismutase, and glutathione peroxidase, and glutathione level, and reduced malondialdehyde level in the liver tissue (Liang et al. 2013).

\section{Hericium as anti-inflammatory agent}

Hetland et al. (2020) reported that Hericium caused a decrease in inflammatory cytokines, oxidative stress, and changed intestinal microorganisms, thus, leading to the anti-allergic mechanism in maintaining the balance of $\mathrm{T}$ helper cells. Hericium induced anti-inflammatory mechanisms also include cytokines that cause inflammation, nerve growth that prevents the death of neurons in the ischemic brain (Lee et al. 2014), growth of beneficial intestinal microbiota protecting against inflammatory bowel disease-induced mucosa damages, and improving host immunity (Diling et al. 2017), regulating oxidative stress through signaling pathways that attenuate colitis (Ren et al. 2018).

\section{Hericium as anti-microbial agent}

The anti-microbial activity of Hericium is diverse due to the different species and their ability to inhabit diverse ecological niches with a variety of nutrients and physiological and biological conditions (Sheng 2017). Kim et al. (2019) reported that the anti-microbial activity of H. erinaceus was highly effective against Staphylococcus aureus, Salmonella enteritidis, Vibrio parahaemolyticus, and Escherichia coli at $2.5 \mathrm{mg} / \mathrm{mL}$ or above. Hence, its extract can be used as food and natural antimicrobial agent in the diet of pathogenic bacteria.

\section{Hericium as anti-viral agent}

Ellan et al. (2019) reported anti-viral activity of $H$. erinaceus. The mushrooms extract showed very prominent anti-dengue virus serotype 2 (DENV-2) activity (Ellan et al. 2019). Wang \& $\mathrm{Ng}$ (2004) found that the low molecular weight laccase from the dried fruiting body of $\mathrm{H}$. erinaceus showed anti-viral activity against human immunodeficiency virus (HIV) and HIV-1.

\section{Economical importance}

Since ancient times, Hericium erinaceus was a popular species due to its nutritional value and traditional medicinal benefits in China (Khan et al. 2013). Hericium has high importance and potential to improve many parts of human life (Valverde et al. 2015). In general, Hericium is saprobic, hence utilizing organic and agricultural wastes are recommended (Marshall \& Nair 2014). Hericium cultivation in some countries is done on a commercial level, earning a handsome income to the growers and farmers (Scherr et al. 2004). The employment generated through cultivation and its associated allied activities is also immense (Jha 2006). Increasing the value of Hericium mushrooms in terms of quality products is another economic avenue (Üstïn et al. 2018).

Hericium is economically important, since the mushrooms are valuable resources for agricultural, food, and medicinal applications (Park et al. 2004). Ergothioneine accumulates at higher levels in mycelia than in fruiting bodies of economically important mushroom species (Lee et al. 2009). Therefore, the mycelial medium is an effective way to increase the anti-oxidant property of economically important mushroom species (Lee et al. 2009). The search for new sources of bioactive products from Hericium is still being done to date (Antunes et al. 2020). 


\section{Industrial and pharmaceutical applications}

The mycelia of Hericium erinaceus are rich in erinacines and could be potential candidates in promoting positive brain and nerve health-related activities ( $\mathrm{Li}$ et al. 2018). Zhang et al. (2017) and Tzeng et al. (2018) reported that $H$. erinaceus powder reduced short-term memory impairment and visual recognition, and neuron generation of the hippocampus of Alzheimer's disease in a mouse model. Also, Hericium have been used to treat cognitive impairment in Parkinson's disease (Kuo et al. 2016, Trovato et al. 2016). In addition, Rascher et al. (2020) reported the cyathane diterpenoid erinacine $\mathrm{C}$ of the genus Hericium induces expression of the neurotrophins NGF and BDNF in glial cells, also the erinacine $\mathrm{C}$ promotes ETS-dependent transcription in astroglial cells, which may play a role in regulating germination and regeneration in the central nervous system.

Commercial health products made from Hericium are commonly used for health care and to promote learning and memory (Sokół et al. 2015). A large list of health care products that contain $H$. erinaceus extract as a medicinal ingredient has been introduced for promoting human health. There are patented health products, meal replacement powders, chewable tablets, and solids beverages containing the compounds of $H$. erinaceus that improve human health without side effects (He et al. 2017).

An only clinical study reported the intake of Hericium as local drugs, herbs, and in medicinal cuisine (Limanaqi et al. 2020). The pharmacological activities, including anti-allergic, antibacterial, anti-fungal, anti-inflammatory, anti-oxidative, anti-viral, cytotoxic, immunomodulating, antidepressive, anti-hyperlipidemic, anti-diabetic, digestive, hepatoprotective, neuroprotective, nephroprotective, osteoprotective, and hypotensive activities (Venturella et al. 2021). In attempts to assess the impact on cognitive function for clinical research, Yamabushitake was used at 750 $\mathrm{mg}$ /day (available as a $250 \mathrm{mg}$ tablet, three-time daily for 16 weeks). The tablet contains $96 \%$ of dry powder of Yamabushitake (Mori et al. 2009). Wang et al. (2014) reported that the Hericium tablet was administered $3 \mathrm{~g} /$ day for 16 weeks and $5 \mathrm{~g} /$ day of fruiting bodies pulp broth were eaten. Most of them have beneficial effects on the body, especially the brain, heart and intestines. Chiu et al. (2018) reported that Hericium may help relieve mild symptoms of anxiety and depression and can reduce the impact of chronic illness.

\section{Conclusion}

Hericium has attracted a lot of attention as an edible mushroom, supplementary food, and potential source of medicinal compounds. It has been cultivated for more than two decades in China. Traditionally used for more than 1,000 years, Hericium was found to have various pharmacological effects. The significance of Hericium in the health and economic sector has led to various industrial applications. Studies have shown successful cultivation of Hericium using both indoor and outdoor cultivation methods. Moreover, submerged culture methods are capable of reducing the cost of downstream processing and increasing the bioactive compound yield. Using the research results and nutraceutical properties of Hericium, it is possible to develop Hericium based products industrially.

\section{Acknowledgements}

We appreciate the kind support given by the Research and Researchers Industries (RRI) (Grant no. PHD62I0018/2562) and Thailand Science Research and Innovation (TSRI) grant "Macro fungi diversity research from the Lancang-Mekong Watershed and surrounding areas" (Grant no. DBG6280009).

\section{References}

Adamant A. 2019 - Lion's mane mushroom (Hericium erinaceus): identification \& uses. https://practicalselfreliance.com/lions-mane-mushroom/ (Accessed on May 25, 2021).

Ahmadi LMJ, Farsi M. 2017 - Evaluation of mycelium growth rate and yield of white button mushroom isolates (Agaricus bisporus) in Iran. Journal of Horticultural Science 31, 99-109. 
Andrew C, Heegaard E, Høiland K, Senn-Irlet B et al. 2018 - Explaining European fungal fruiting phenology with climate variability. Ecology 99, 1306-1315.

Antunes F, Marçal S, Taofiq O, MMB Morais A et al. 2020 - Valorization of mushroom byproducts as a source of value-added compounds and potential applications. Molecules 25, 2672.

Atila F, Tüzel Y, Faz Cano A, Fernandez JA. 2017 - Effect of different lignocellulosic wastes on Hericium americanum yield and nutritional characteristics. Journal of the Science of Food and Agriculture 97, 606-612.

Atila F, Tuzel Y, Fernández JA, Cano AF et al. 2018 - The effect of some agro-industrial wastes on yield, nutritional characteristics and antioxidant activities of Hericium erinaceus isolates. Scientia Horticulturae 238, 246-254.

Atila F, Tüzel YÜK SEL, Pekşen A, Cano AF et al. 2021 - The effect of different fruiting temperatures on the yield and nutritional parameters of some wild and hybrid Hericium isolates. Scientia Horticulturae 280, 109915.

Atila F. 2019 - Lignocellulosic and proximate based compositional changes in substrates during cultivation of Hericium erinaceus mushroom. Scientia Horticulturae 258, 108779.

Badalyan SM. 2003 - Edible and medicinal higher Basidiomycetes mushrooms as a source of natural antioxidants. International Journal of Medicinal Mushrooms 5, 153-163.

Blagodatski A, Yatsunskaya M, Mikhailova V, Tiasto V et al. 2018 - Medicinal mushrooms as an attractive new source of natural compounds for future cancer therapy. Oncotarget 9, 29259.

Bruhn JN, Kozak ME, Krawczyk J. 2000 - Woodland specialty mushrooms: who grows them and what are the problems. Mushroom Science 15, 535-542.

Bunroj A, Sawasdikarn J, Rassami W. 2017 - Research and development project of Monkey's Head mushroom (Hericium erinaceus) cultivation in East of Thailand. International Journal of Agricultural Technology 13, 1529-1535.

Chen J, Zeng X, Yang YL, Xing YM et al. 2017 - Genomic and transcriptomic analyses reveal differential regulation of diverse terpenoid and polyketides secondary metabolites in Hericium erinaceus. Scientific Reports 7, 1-14.

Chen ZG, Bishop KS, Tanambell H, Buchanan P et al. 2019 - Assessment of in vitro bioactivities of polysaccharides isolated from Hericium Novae-Zealandiae. Antioxidants 8, 211.

Chiu CH, Chyau CC, Chen CC, Lee LY et al. 2018 - Erinacine A-enriched Hericium erinaceus mycelium produces antidepressant-like effects through modulating BDNF/PI3K/Akt/GSK-3 $\beta$ signaling in mice. International Journal of Molecular Sciences 19, 341.

Chong PS, Fung ML, Wong KH, Lim LW. 2020 - Therapeutic potential of Hericium erinaceus for depressive disorder. International Journal of Molecular Sciences 21, 163.

Croan SC. 2004. Conversion of conifer wastes into edible and medicinal mushrooms. Forest Products Journal 54, 68-76.

Cui F, Liu Z, Li Y, Ping L et al. 2010 - Production of mycelial biomass and exo-polymer by Hericium erinaceus CZ-2: optimization of nutrients levels using response surface methodology. Biotechnology and Bioprocess Engineering 15, 299-307.

Dai J, Dong H. 2014 - Intensive cotton farming technologies in China: Achievements, challenges and countermeasures. Field Crops Research 155, 99-110.

Das K, Stalpers J, Eberhardt U. 2011 - A new species of Hericium from Sikkim Himalaya (India). Cryptogamie, Mycologie 32, 285-293.

De Silva DD, Rapior S, Sudarman E, Stadler M et al. 2013 - Bioactive metabolites from macrofungi: Ethnopharmacology, biological activities and chemistry. Fungal Diversity 62, 140.

Diling C, Xin Y, Chaoqun Z, Jian Y et al. 2017 - Extracts from Hericium erinaceus relieve inflammatory bowel disease by regulating immunity and gut microbiota. Oncotarget 8 , 85838 .

Elisashvili VI. 2012 - Submerged cultivation of medicinal mushrooms: bioprocesses and products. International Journal of Medicinal Mushrooms 14, 211-239. 
Elkhateeb WA, Daba GM, Thomas PW, Wen TC. 2019 - Medicinal mushrooms as a new source of natural therapeutic bioactive compounds. Egyptian Pharmaceutical Journal 18, 88-101.

Ellan K, Thayan R, Raman J, Hidari KI et al. 2019 - Anti-viral activity of culinary and medicinal mushroom extracts against dengue virus serotype 2: an in-vitro study. BMC Complementary and Alternative Medicine, 19, 1-12.

Fernandes T, Garrine C, Ferrão J, Bell V et al. 2021 - Mushroom nutrition as preventative healthcare in uub-Saharan Africa. Applied Sciences 11, 4221.

Friedman M. 2015 - Chemistry, nutrition, and health-promoting properties of Hericium erinaceus (Lion's Mane) mushroom fruiting bodies and mycelia and their bioactive compounds. Journal of Agricultural and Food Chemistry 63, 7108-7123.

Grace J, Mudge KW. 2015 - Production of Hericium sp. (lion's mane) mushrooms on totem logs in a forest farming system. Agroforestry Systems 89, 549-556.

Hallenberg N, Nilsson RH, Robledo G. 2012 - Species complexes in Hericium (Russulales, Agaricomycota) and a new species - Hericium rajchenbergii - from southern South America. Mycological Progress 12, 413-20.

Hassan FRH. 2007 - Cultivation of the monkey head mushroom (Hericium erinaceus) in Egypt. Journal of Applied Sciences Research 3, 1229-1233.

He MQ, Zhao RL, Hyde KD, Begerow D et al. 2019 - Notes, outline and divergence times of Basidiomycota. Fungal Diversity 99, 105-367.

He X, Wang X, Fang J, Chang Y et al. 2017 - Structures, biological activities, and industrial applications of the polysaccharides from Hericium erinaceus (Lion's Mane) mushroom: A review. International Journal of Biological Macromolecules 97, 228-237.

Heleno SA, Barros L, Martins A, Queiroz MJR et al. 2015 - Chemical composition, antioxidant activity and bioaccessibility studies in phenolic extracts of two Hericium wild edible species. LWT-Food Science and Technology 63, 475-481.

Hetland G, Tangen JM, Mahmood F, Mirlashari MR et al. 2020 - Antitumor, anti-inflammatory and antiallergic effects of Agaricus blazei mushroom extract and the related medicinal basidiomycetes mushrooms, Hericium erinaceus and Grifola frondosa: A review of preclinical and clinical studies. Nutrients 12, 1339.

Ho LH, Zulkifli NA, Tan TC. 2020 - Edible mushroom: Nutritional properties, potential nutraceutical values, and its utilisation in food product development. An Introduction to Mushroom 19-38.

Hu SH, Wang JC, Wu CY, Hsieh SL et al. 2008 - Bioconversion of agro wastes for the cultivation of the culinary-medicinal lion's mane mushrooms Hericium erinaceus (Bull.: Fr.) Pers. and H. laciniatum (Leers) Banker (Aphyllophoromycetideae) in Taiwan. International Journal of Medicinal Mushrooms 10, 385-398.

Imtiaj A, Rahman SA. 2008 - Economic viability of mushrooms cultivation to poverty reduction in Bangladesh. Tropical and Subtropical Agroecosystems 8, 93-99.

Index Fungorum 2021 - http://www.indexfungorum.org/ (Accessed on July 6, 2021).

Jha B. 2006 - Employment, wages, and productivity in Indian agriculture. Delhi: Institute of Economic Growth.

Jiang S, Liu S, Qin M. 2019 - Effects of extraction conditions on crude polysaccharides and antioxidant activities of the lion's mane medicinal mushroom, Hericium erinaceus (Agaricomycetes). International Journal of Medicinal Mushrooms 21, 1007-1018.

Jiang S, Wang S, Sun Y, Zhang Q. 2014 - Medicinal properties of Hericium erinaceus and its potential to formulate novel mushroom-based pharmaceuticals. Applied Microbiology and Biotechnology 98, 7661-7670.

Keong CY, Rashid BAA, Ing YS, Ismail Z. 2007 - Quantification and identification of polysaccharide contents in Hericium erinaceus. Nutrition \& Food Science 37, 260-271.

Khan MA, Tania M, Liu R, Rahman MM. 2013 - Hericium erinaceus: an edible mushroom with medicinal values. Journal of Complementary and Integrative Medicine 10, 253-258.

Kim MU, Lee EH, Jung HY, Lee SY et al. 2019 - Inhibitory activity against biological activities 
and antimicrobial activity against pathogenic bacteria of extracts from Hericium erinaceus. Journal of Applied Biological Chemistry 62, 173-179.

Kirk PM, Cannon PF, Stalpers J, Minter DW. 2008 - Dictionary of the Fungi 10th ed.-CABI.

Ko HG, Park HG, Park SH, Choi CW et al. 2005 - Comparative study of mycelial growth and basidiomata formation in seven different species of the edible mushroom genus Hericium. Bioresource Technology 96, 1439-1444.

Kulisic T, Radonic A, Katalinic V, Milos M. 2004 - Use of different methods for testing antioxidative activity of oregano essential oil. Food Chemistry 85, 633-640.

Kuo HC, Lu CC, Shen CH et al. 2016 - Hericium erinaceus mycelium and its isolated erinacine A protection from MPTP-induced neurotoxicity through the ER stress, triggering an apoptosis cascade. Journal of Translational Medicine 14, 1-14.

Kuo M. 2014 - The Genus Hericium. http://mushroomexpert.com/hericium.html (Accessed October 6, 2020).

Lee BC, Bae JT, Pyo HB, Choe TB et al. 2004 - Submerged culture conditions for the production of mycelial biomass and exopolysaccharides by the edible Basidiomycete Grifola frondosa. Enzyme and Microbial Technology 35, 369-376.

Lee KF, Chen JH, Teng CC, Shen CH et al. 2014 - Protective effects of Hericium erinaceus mycelium and its isolated erinacine A against ischemia-injury-induced neuronal cell death via the inhibition of iNOS/p38 MAPK and nitrotyrosine. International Journal of Molecular Sciences $15,15073-15089$.

Lee SL, Leong JY, Lim LH. 2010 - Comparative cytotoxicity and hemagglutination activities of crude protein extracts from culinary medicinal mushrooms. International Journal of Medicinal Mushrooms 12, 213-222.

Lee WY, Park EJ, Ahn JK, Ka KH. 2009 - Ergothioneine contents in fruiting bodies and their enhancement in mycelial cultures by the addition of methionine. Mycobiology 37, 43-47.

Li G, Yu K, Li F, Xu K et al. 2014 - Anticancer potential of Hericium erinaceus extracts against human gastrointestinal cancers. Journal of Ethnopharmacology 153, 521-530.

Li I, Lee LY, Tzeng TT, Chen WP et al. 2018 - Neurohealth properties of Hericium erinaceus mycelia enriched with erinacines. Behavioural Neurology, 1-10.

Liang B, Guo Z, Xie F, Zhao A. 2013 - Antihyperglycemic and antihyperlipidemic activities of aqueous extract of Hericium erinaceus in experimental diabetic rats. BMC Complementary and Alternative Medicine 13, 1-7.

Limanaqi F, Biagioni F, Busceti CL, Polzella M et al. 2020 - Potential antidepressant effects of Scutellaria baicalensis, Hericium erinaceus and Rhodiola rosea. Antioxidants 9, 234.

Liu Z, Li M, Yan P, Zhu Z et al. 2019 - Transcriptome analysis of the effects of Hericium erinaceus polysaccharide on the lymphocyte homing in Muscovy duck reovirus-infected ducklings. International Journal of Biological Macromolecules 140, 697-708.

Malinowska E, Krzyczkowski W, Herold F, Lapienis G et al. 2009 - Biosynthesis of selenium containing polysaccharides with antioxidant activity in liquid culture of Hericium erinaceum. Enzyme and Microbial Technology 44, 334-343.

Marshall E, Nair N. 2014 - Make Money by Growing Mushrooms: Food and Agriculture Organization of the United Nations, Rome.

Miles PG, Chang ST. 2004 - Mushrooms: cultivation, nutritional value, medicinal effect, and environmental impact. CRC press.

Miyazawa M, Takahashi T, Horibe I, Ishikawa R. 2012 - Two new aromatic compounds and a new D-arabinitol ester from the mushroom Hericium erinaceum. Tetrahedron 68, 2007-2010.

Mori K, Inatomi S, Ouchi K, Azumi Y et al. 2009 - Improving effects of the mushroom Yamabushitake (Hericium erinaceus) on mild cognitive impairment: a double-blind placebocontrolled clinical trial. Phytotherapy Research 23, 367-372.

Mykoweb 2015 - Hericium sp. http://www.mykoweb.com/CAF/species/Hericium_abietis.html (Accessed October 6, 2020) 
Oei P (Ed.). 2016 - Mushroom cultivation IV: Appropriate Technology for Mushroom Growers. ECO Consult Foundation.

Ouali Z, Sbissi I, Boudagga S, Rhaiem A et al. 2020 - First report of the rare tooth fungus Hericium erinaceus in North African temperate forests. Plant Biosystems-An International Journal Dealing with all Aspects of Plant Biology 154, 24-28.

Park HG, Ko HG, Kim SH, Park WM. 2004 - Molecular identification of Asian isolates of medicinal mushroom Hericium erinaceum by phylogenetic analysis of nuclear ITS rDNA. Journal of Microbiology and Biotechnology 14, 816-821.

Pathmashini L, Arulnandhy V, Wijeratnam RW. 2008 - Cultivation of oyster mushroom (Pleurotus ostreatus) on sawdust. Ceylon Journal of Science (Biological Sciences) 37, 177-182.

Persoon CH. 1794 - Neuer Versuch einer systematischen Eintheilung der Schwämme. Römer's Neues Magazin für die Botanik 1, 63-80.

Rascher M, Wittstein K, Winter B, Rupcic Z et al. 2020 - Erinacine C activates transcription from a consensus ETS DNA binding site in Astrocytic cells in addition to NGF induction. Biomolecules 10, 1440.

Ratto D, Corana F, Mannucci B, Priori EC et al. 2019 - Hericium erinaceus improves recognition memory and induces hippocampal and cerebellar neurogenesis in frail mice during aging. Nutrients 11, 715.

Ren Y, Geng Y, Du Y, Li W et al. 2018 - Polysaccharide of Hericium erinaceus attenuates colitis in C57BL/6 mice via regulation of oxidative stress, inflammation-related signaling pathways and modulating the composition of the gut microbiota. The Journal of Nutritional Biochemistry 57, 67-76.

Rupcic Z, Rascher M, Kanaki S, Köster RW et al. 2018 - Two new cyathane diterpenoids from mycelial cultures of the medicinal mushroom Hericium erinaceus and the rare species, Hericium flagellum. International Journal of Molecular Sciences 19, 740.

Ryu SH, Hong SM, Khan Z, Lee SK et al. 2021 - Neurotrophic isoindolinones from the fruiting bodies of Hericium erinaceus. Bioorganic \& Medicinal Chemistry Letters 31, 127714.

Sangtitanu T, Sangtanoo P, Srimongkol P, Saisavoey T et al. 2020 - Peptides obtained from edible mushrooms: Hericium erinaceus offers the ability to scavenge free radicals and induce apoptosis in lung cancer cells in humans. Food \& Function 11, 4927-4939.

Sawant A. 2021 - Commercial Mushroom Cultivation Guide 2021. Agriculture Guruji. https://agricultureguruji.com/mushroom-cultivation/ (Accessed August 16, 2021).

Scherr SJ, White A, Kaimowitz D. 2004 - 8. Making markets work for forest communities. Columbia University Press, 130-155.

Shao S, Wang D, Zheng W, Li X et al. 2019 - A unique polysaccharide from Hericium erinaceus mycelium ameliorates acetic acid-induced ulcerative colitis rats by modulating the composition of the gut microbiota, short chain fatty acids levels and GPR41/43 respectors. International immunopharmacology 71, 411-422.

Sheng X, Yan J, Meng Y, Kang Y et al. 2017 - Immunomodulatory effects of Hericium erinaceus derived polysaccharides are mediated by intestinal immunology. Food \& Function 8, 1020 1027.

Soderberg C. 2019 - Mushroom cultivation: An illustrated guide to growing your own mushrooms at home. International Journal of Medicinal Mushrooms 21.

Sokół S, Golak-Siwulska I, Sobieralski K, Siwulski M et al. 2015 - Biology, cultivation, and medicinal functions of the mushroom Hericium erinaceum. Acta Mycologica 50, 1069.

Song X, Gaascht F, Schmidt-Dannert C, Salomon CE. 2020 - Discovery of antifungal and biofilm preventative compounds from mycelial cultures of a unique North American Hericium sp. fungus. Molecules 25, 963.

Stamets P. 2011 - Growing gourmet and medicinal mushrooms. Ten speed press.

Suwanno S, Aminoh AYAE, Suwanno N. 2019 - Utilization of paper-cone water cups as an alternative lignocellulose waste substrate in Pleurotus ostreatus production. Walailak Journal of Science and Technology (WJST) 16, 780-790. 
Suzuki C, Mizuno T. 1997 - XI. Cultivation of yamabushitake (Hericium erinaceum). Food Reviews International 13, 419-421.

Thongbai B, Rapior S, Hyde KD, Wittstein K et al. 2015 - Hericium erinaceus, an amazing medicinal mushroom. Mycological Progress 14, 1-23.

Trovato A, Siracusa R, Di Paola R et al. 2016 - Redox modulation of cellular stress response and lipoxin A4 expression by Hericium erinaceus in rat brain: relevance to Alzheimer's disease pathogenesis. Immunity \& Ageing 13, 1-11.

Tzeng TT, Chen CC, Chen CC, Tsay HJ et al. 2018 - The cyanthin diterpenoid and sesterterpene constituents of Hericium erinaceus mycelium ameliorate Alzheimer's disease-related pathologies in APP/PS1 transgenic mice. International Journal of Molecular Sciences 19, 598.

Ulziijargal E, Mau JL. 2011 - Nutrient compositions of culinary-medicinal mushroom fruiting bodies and mycelia. International journal of medicinal mushrooms 13, 343-349.

Üstün NŞ, Bulam S, Pekșen A. 2018 - The use of mushrooms and their extracts and compounds in functional foods and nutraceuticals. Türkmen, A.(ed.) 1, 1205-1222.

Valverde ME, Hernández-Pérez T, Paredes-López O. 2015 - Edible mushrooms: improving human health and promoting quality life. International Journal of Microbiology 2015, 14.

Vamanu E, Voica A. 2017 - Total phenolic analysis, antimicrobial and antioxidant activity of some mushroom tinctures from medicinal and edible species, by in vitro and in vivo tests. Scientific Bulletin Series F. Biotechnologies 21, 318-324.

Venturella G, Ferraro V, Cirlincione F, Gargano ML. 2021 - Medicinal mushrooms: bioactive compounds, use, and clinical trials. International Journal of Molecular Sciences 22, 634.

Volk T, Westmoreland S. 2009 - Hericium americanum, the pom pon mushroom, a.k.a. Lion's mane, the bear's head tooth fungus, monkey head, or for this month, the icicle mushroom. https://botit.botany.wisc.edu/toms_fungi/jan2003.html (Retrieved 27 June 2009).

Wang HX, Ng TB. 2004 - A new laccase from dried fruiting bodies of the monkey head mushroom Hericium erinaceum. Biochemical and Biophysical Research Communications 322, 17-21.

Wang M, Gao Y, Xu D, Konishi T et al. 2014 - Hericium erinaceus (Yamabushitake): a unique resource for developing functional foods and medicines. Food \& Function 5, 3055-3064.

Wang XY, Zhang DD, Yin JY, Nie SP et al. 2019 - Recent developments in Hericium erinaceus polysaccharides: extraction, purification, structural characteristics and biological activities. Critical Reviews in Food Science and Nutrition 59, 96-115.

Wittstein K, Rascher M, Rupcic Z, Löwen E et al. 2016 - Corallocins A-C, nerve growth and brain-derived neurotrophic factor inducing metabolites from the mushroom Hericium coralloides. Journal of Natural Products 79, 2264-2269.

Wolters N, Schembecker G, Merz J. 2015 - Erinacine C: a novel approach to produce the secondary metabolite by submerged cultivation of Hericium erinaceus. Fungal Biology 119, 1334-1344.

Wu T, Xu BB. 2015 - Antidiabetic and antioxidant activities of eight medicinal mushroom species from China. International Journal of Medicinal Mushrooms 17, 129-140.

Xiao G, Chapman B. 1997 - Cultivation of Hericium abietis on conifer sawdust. Canadian Journal of Botany 75, 1155-1157.

Yao F, Gao H, Yin CM, Shi DF et al. 2021 - Evaluation of In Vitro antioxidant and antihyperglycemic activities of extracts from the Lion's Mane medicinal mushroom, Hericium erinaceus (Agaricomycetes). International Journal of Medicinal Mushrooms 23, 55-66.

Younis AM. 2017 - Anticancer potential of Hericium erinaceus extracts against particular human cancer cell lines. Microbial Biosystems 2, 9-20.

Zhang CC, Cao CY, Kubo M, Harada K et al. 2017 - Chemical constituents from Hericium erinaceus promote neuronal survival and potentiate neurite outgrowth via the TrkA/Erk1/2 pathway. International Journal of Molecular Sciences 18, 1659. 
Zhang J, An S, Hu W, Teng M et al. 2016 - The neuroprotective properties of Hericium erinaceus in glutamate-damaged differentiated PC12 cells and an Alzheimer's disease mouse model. International Journal of Molecular Sciences 17, 1810.

Zhang J. 2000 - Study on the experiment for the cultivation of Hericium erinaceus with corn cobs. Edible Fungi of China 19, 14-15.

Zhang Z, Lva G, Pana H, Pandeyb A et al. 2012 - Antioxidant and hepatoprotective potential of endo-polysaccharides from Hericium erinaceus grown on tofu whey. International Journal of Biological Macromolecules 51, 1140-1146. 